\title{
Guiding Students Learning Project Team Management from Their Own Practice
}

\author{
Wanwu Guo \\ Edith Cowan University, Perth, Australia
}

w.guo@ecu.edu.au

\begin{abstract}
Project development is scheduled in the final year study of undergraduate students in computer science, software engineering, information technology, and other relevant programs. This final project provides students an opportunity to integrate all the skills and knowledge learnt from their previous studies into real practice. Experience in supervising student projects shows that student's ability in working collaboratively in a teamwork environment is the most influential factor on the quality of a student project. However, managing a student project team is significantly different from managing a real project in a workplace. This paper reports the practice of guiding students handling internal collaboration in a team environment during IT project development. Firstly, a practical guideline in dealing with human incompatibility in a project team is introduced to students in the beginning of their project development. During the course, when an event occurs, except in some extreme circumstances, the supervisor only gives students advice on all the possible solutions and their corresponding consequences according to the nature of the event. It is the students in the project team who make the final decision on which action they should take on resolving the problem encountered. This gives students more responsibility in managing their own project team, from which students will learn much more in handling human-related issues effectively than from textbooks. The case studies presented in this paper show that this approach is useful.
\end{abstract}

Keywords: Student IT Project, Project Team Management, Project Supervision, Principles and Tactics, Human incompatibility

\section{Introduction}

In the final year study in computer science, software engineering, and information technology, students are required to complete a teamwork-based project. To this stage, it is assumed that students have taken many fundamental and specialised subjects/units that enable students to initiate and carry out an appropriate project. For example, in the School of Computer and Information Science at Edith Cowan University, by completing units on systems analysis, object-oriented analysis and design, and database design, students should gain skills in project analysis and design; by finishing units on software engineering, project management, and professionalism, students should obtain required skills in project planning, management and working in a team envi-

Material published as part of this journal, either on-line or in print, is copyrighted by Informing Science. Permission to make digital or paper copy of part or all of these works for personal or classroom use is granted without fee provided that the copies are not made or distributed for profit or commercial advantage AND that copies 1 ) bear this notice in full and 2) give the full citation on the first page. It is permissible to abstract these works so long as credit is given. To copy in all other cases or to republish or to post on a server or to redistribute to lists requires specific permission from the publisher at Publisher@InformingScience.org ronment; skills in coding, testing, and implementation are acquired from studying units on programming, database, networking, internetworking, and interactive Web development. It is this final project that integrates all the knowledge and skills learnt from these individual units into a collection of 
deliverables as a project.

Experience in supervising student project development has shown that application of the knowledge and skills mainly gained from theories to a practical project is not as easy as students may have thought in the beginning of their project. Technical problems are often encountered during the course, but most students are able to overcome them gradually. It is the student's ability in working collaboratively in a teamwork environment that is the most influential factor on the quality of a student project. Usually a project team working in a collaborative environment will produce a high-standard project that fulfils the proposed project objectives on time whereas a project team with internal turmoil throughout the course always struggles to reach the basic requirements for passing this project-oriented unit. This demonstrates that dealing with the 'social' issues associated with a project team is more difficult than overcoming 'technical' issues encountered during the project development for students. These 'social' skills can only be learnt from student's practice in a teamwork environment. Therefore, guiding students working collaboratively within a project team is one of the major tasks in supervising student projects.

How to manage an IT project team in real workplace has been well documented in many publications (eg, Gustafson, 2002; Hall, 1998; Hartley, 2003; Jones, 1994; Pressman, 2001; Sommerville, 2001). However, managing a student IT project team is significantly different from managing a real project in a workplace.

Firstly, the purpose of a student project is to provide students an analogous environment to learn project management skills and work effectively in a team environment. Therefore, faults are expected and tolerable during the course. Actually, students can learn more practical knowledge from their mistakes. In contrast, the purpose of a commercial project in the real world is to get financial gains from delivering a product satisfied with the requirements predefined in the contract between the client and developer. Any fault occurred during the course would cause financial losses to some extent or damages to developer's reputation.

Secondly, the final assessment for a student project is not only based on the completion of the project, but also a number of other aspects of the project during the course, such as project selection and planning, risk identification and mitigation, process management and implementation, quality control and assurance, and collaboration in a teamwork environment. Some student projects with dissatisfaction in their final products can still be considered to pass this subject with project degradation, based on the fact that students have got the necessary practice in project management and development during the project. However, for a commercial project, no such an assessment exists; instead, it is either a success or a failure only based on the final product, regardless other aspects during the course.

The other major difference is in managing the project team. In a student project, the relation between the team leader and team members has less authority than that in a workplace. Therefore, handling human conflicts in a student project is totally different from what has been described in many books in managing a project team in the real world.

This paper reports the practice in guiding students handling internal collaboration in a team environment during project development. Firstly, a practical guideline in dealing with human incompatibility in a project team is introduced to students in the beginning of their project development. During the course, when an event occurs, except in extreme circumstances, the supervisor only gives students advice on all the possible solutions and their corresponding consequences according to the nature of the event. It is the students in the project team who make the final decision on which action they should take on resolving the problem encountered. This gives students more responsibility in managing their own practice, from which students will learn much more in handling human-related issues effectively. The case studies presented in this paper show that this approach is useful. 


\section{Common Human Conflicts in Student Project Development}

Human incompatibility in a team environment is a special kind of risk in project management. Handling human incompatibility aims to minimise its effect on any kind of project development. This is especially vital for those projects that are carried out by a group of students who are inexperienced in working in a teamwork environment. Human incompatibility in a team environment may come from the following aspects in any project development, including student project:

Tension between the team leader and members,

Slower progress from a particular member, and

Upset caused by cultural or religious differences.

In addition, a special case in student project management could be the sudden departure of a team member from the project in a late stage, which may lead to the incompletion, even the failure of the project. This is because there is no 'spare student' available to fill in the vacancy left by the student who quits the team. This should not be a serious problem in a workplace because the vacancy can be quickly filled by another capable professional.

\section{A Practical Guideline for Handling Human Incompatibility in a Team Environment}

Normally a project team should have 4-5 students, in which there should be members who are excellent in programming, management, and documentation. If any team does not meet this requirement, regrouping should take place.

A modified software development model based on Waterfall model (Royce, 1970) is recommended to all the project teams to guide their project planning, although other models are also introduced (eg, Boehm, 1988; Parnas, 1979). This modified model is appropriate for a project that should be completed in a fixed duration of 14 weeks for the students.

During the supervision of student projects, a practical guideline based on a principle-tactics strategy is proposed and recommended to students for handling each of the above risky events in human incompatibility in a team environment.

In practice, the principle and tactics are explicitly explained to students in the beginning of their projects so that they can use them as a general guide in managing their project. During project development, whenever an event occurs, in most occasions the supervisor only gives advice to students in relation to some outlined tactics and their consequences to the project. Students in the team then make the decision on which action they should take on resolving the event encountered.

A project manager in a real workplace has many influential measures to control the progress of a real project, such as commanding a member to change his/her original assignment, giving bonus or fines to team members according to their personal performances, making personnel change necessary to the project, promoting the excellent performers to higher positions, discontinuing incapable member's contract, et al. However, the only effective measure for a supervisor to influence the progress of student projects is to make the student's performances in reference to the final assessment of their projects. According to regulations in some universities, a student can withdraw from a unit/subject almost at any time with a maximum punishment as losing the tuition fee paid without academic penalty to that unit/subject. He/She can then take the same study in another semester. Therefore, when a student in a project team feels that he/she is forced to do something that he/she cannot or does not want to do, he/she may decide to withdraw from the 
project. This may lead to the incompletion, even the failure of a project, which is a great unfairness to the rest of the team. Therefore, it is a sensible and important measure to give students more responsibility in making decisions by themselves in the light of the supervisor's advice.

\section{Principle for Handling Human Incompatibility in a Team Environment}

The principle for handling all risks in human incompatibility in a student IT project team is: to establish a harmonic team environment based on respect, responsibility, and tolerance.

All members in a team should respect: 1 ) any agreement made in the team meetings; 2) each other's opinions on, suggestions to, and efforts on the project; 3) individual's working plans under the general team plan; 4) individual's personality, privacy, culture and/or religion. In particular, the team leader should realise that he or she is also a member of the team and should share the workload. Thus the leader should never dictate other members. On the other hand, members should complete any agreed assignments on time and promptly feed back their constructive suggestions to the leader.

The mutual respect in a team can be achieved effectively by each member actively taking full charge of his/her own responsibility in the team. Others will truly respect you unless you have demonstrated to them that you complete your own assignments to the project consistently and timely. Therefore, responsibility is the adequate condition to achieve mutual respect in a team.

Some members in a team can quickly get into their roles and act effectively whereas others may need a longer time to get settled into a new role. After a slower start, the latter may be able to handle their tasks as good as any others. Sometimes, a member may delay the completion of his/her early allocation due to some special reasons, but may have tried his/her best to minimise the influence caused by such a delay. For all these cases, tolerance on some acceptable and reasonable errors or delays during the course is very important to establish and maintain mutual respect and thus achieve the project goals in a team environment. Therefore, tolerance is the necessary condition to achieve mutual respect in a team. Under this principle, tactics for the commonly encountered risks can be taken logically.

\section{Tactics for Handling Tensions between the Team Leader and Members}

In case there is a tension between the team leader and members, it means that all or majority of the members in the team are feeling uncomfortable with their team leader. There are four possibilities depending on the degree of the tension. The tactics for handling these four possibilities is illustrated in Figure 1.

In the best case in which members have not lost their trust in the team leader, the supervisor should promptly advise the team leader to change his/her leadership style to make the members feel comfortable with him/her. If the team leader can adopt a right change in leadership style, he/she will win back the respect from his/her team members. Consequently, the tension between the team leader and members is eliminated without any negative effect on the project. As a result, there should be no penalty to this project on this issue in the final project assessment.

The worse case is that members have partly lost their trust in the team leader and even a change in leadership style cannot win back the full respect from all the members. However, the members still commit to finishing the project under the current leadership. This sometimes occurs during the late stage of the project development when there is no time to make any affordable change in reality. The best advice for the supervisor to give to the project team in this case is to ensure that a working relationship in the team is maintained throughout the remaining period of the project. 


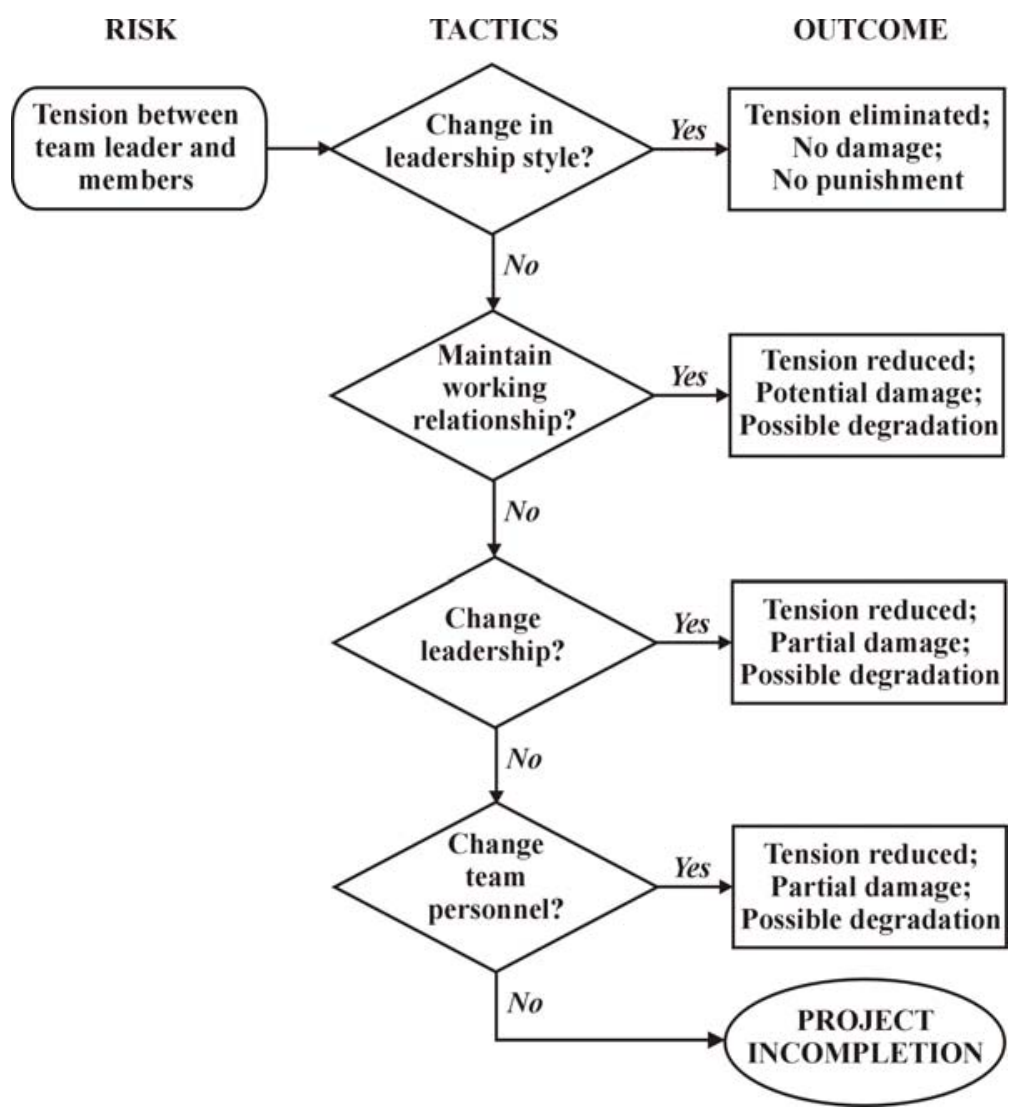

Figure 1: Tactics for handling tensions between the team leader and members.

This requires a high level of tolerance between the team leader and members based on professionalism and ethics. Everyone should realise that in this circumstance any more conflict would lead to severe damage to the project. This consequently means a possible degradation of the project in the final assessment.

Even much worse is that the members have lost their trust in the team leader and demand a change in leadership. This could occur in any stage of the project development. It is a result of members losing respect to the team leader. Thus the supervisor can do nothing on keeping the current leadership, instead, should advise the team to re-establish at least a working relationship in the team if the former team leader stays with the team. This also requires a high level of tolerance between all the members based on professionalism and ethics. Changing leadership means changing the management style, task reallocation, and possible replanning. Therefore, partly loss of previous effort is inevitable. Given the fact that the time frame for the project development is fixed, losing some effort means loss of time. This implies that some proposed requirements may not be fulfilled in the end of the project. Consequently there could be a potential degradation of the project in the final assessment.

The worst case is that a change in team personnel is inevitable. This could occur when the former team leader has to depart from the team, or when a team member may not able to collaborate with other team members, including the team leader. The latter occurs when a member strongly opposes the project plan that is accepted by other members. When either event occurs, necessary adjustment on project requirements is required. If this happens in the early stage of the project, its effect would be minimal because no much effort would have been lost. If this happens in the middle or late stage of the project, losing a team member means the loss of all contributions so far 
from that particular member. This will lead to some degree of project incompletion or project degradation even the supervisor gives the permission to adjust some proposed requirements of the project. In this circumstance, the relaxation on project requirements granted by the supervisor is to ensure that the remaining project team still has sensible practice in project development, rather than ensure the quality of the project.

Beyond the worst case is that even a relaxation on project requirements cannot rescue the project. An incompletion of the project is thus inevitable.

\section{Tactics for Handling Slower Progress from a Particular Member}

Slower progress from a particular member could be due to some unpredictable factors, such as illness, family emergency, or accidents. In such a case, the team leader should firstly check whether that member can catch up the pace by working overtime within an acceptable period to the project plan. Otherwise a backup member should joint the mission temporarily to speed up the catching up. In either case, no requirement on changes in the original plan is needed. Thus there is no punishment applied to the project in the final assessment (Figure 2).

If the slower progress is due to the lack of capability of the member in carrying out the allocated task, a reallocation of tasks in the team is inevitable. This may cause potential delay in project completion. Despite this negativity, this action is necessary because it reduces the negative impact caused by an incapable member on the project to minimal. Without taking such an action, the project would be incomplete. Therefore, punishment may not be applied to such a project that is completed by making extra effort for a rescue mission, even though the quality of the final product may be below the proposed standard.

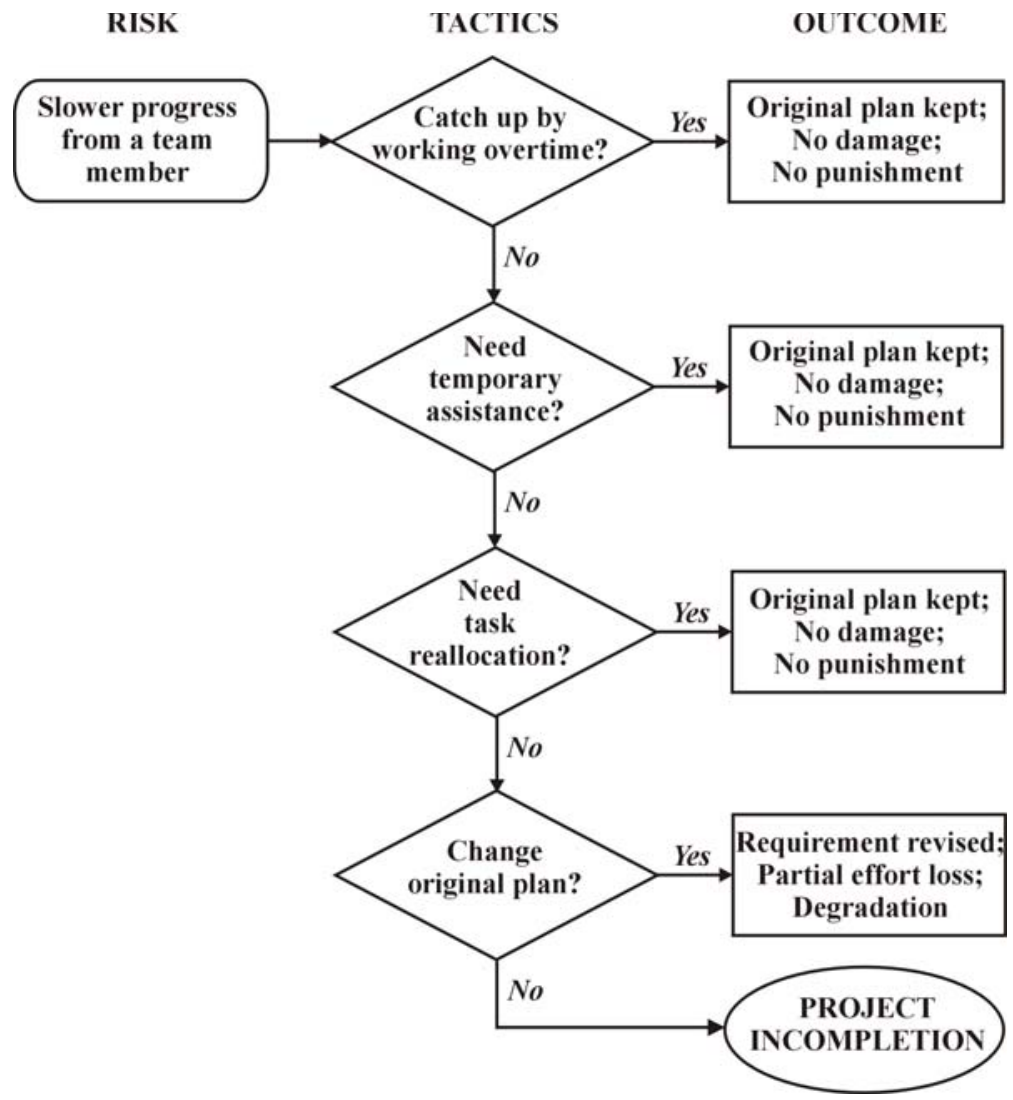

Figure 2: Tactics for handling slower progress from a particular member. 
If this problem is identified too late to take any effective and remedial actions in maintaining the original requirements and plan, the supervisor may give permission to the team for relaxing the original requirements and plan. This arrangement will ensure that the team still has useful practice on project development. However, the consequence for such a relaxation is that the project will be degraded compared with other on-target projects. Final assessment on such a project will be made based on the actual achievement the project made according to its original proposal.

\section{Tactics for Handling Upset Caused by Cultural/Religious Differences}

In a team environment at an international institution, students from different countries with different cultures or religions are likely to work together in a team. As a result, potential conflicts in cultural or religious differences may cause discomfort among team members during the course.

As always more communications among team members will reduce the possibility of occurrence of conflicts associated with cultural and/or religious differences between students. With further understanding between the members, some potential activities/actions that could be misinterpreted by other members with different cultural/religious backgrounds can be avoided. If there is no compatibility between a few members in a team in this regard, the supervisor should arrange possible adjustment in team personnel as early as possible (Figure 3).

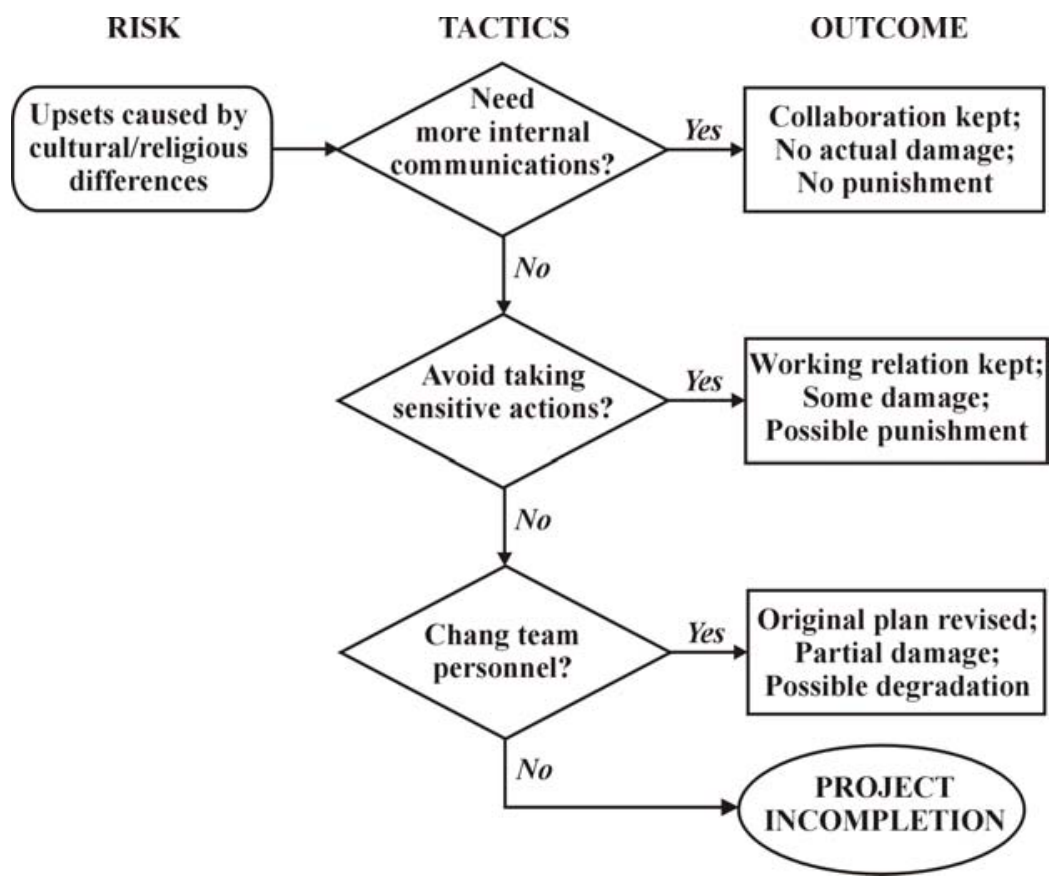

Figure 3: Tactics for handling upset caused by cultural/religious differences.

\section{Tactics for Handling Sudden Withdrawal of a Team Member}

A sudden withdrawal of a member from a project due to various reasons, including human conflicts in the team, is another typical risk encountered in student project development. Once this occurs, if the remaining members believe that they can still carry on their project without major amendment on their original proposal, they are encouraged to do so with potential bonus awarded. If major amendment is indeed required, the supervisor should give permission for taking such an action without potential punishment on this matter (Figure 4). 


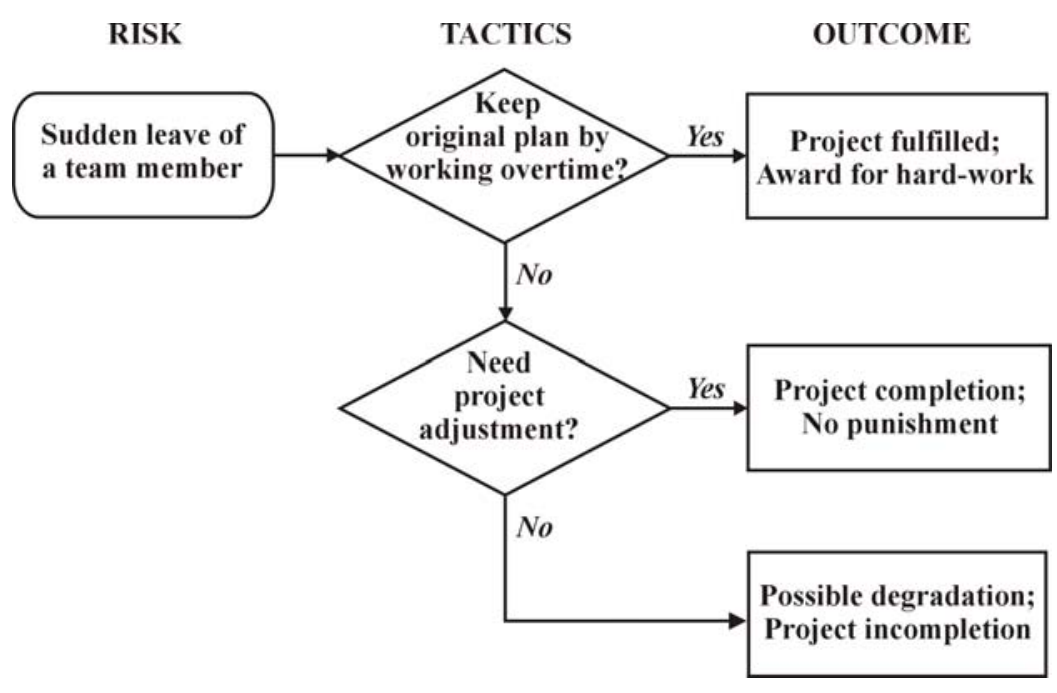

Figure 4: Tactics for handling sudden leave of a team member.

\section{Case Studies}

The cases presented in this section are from the student projects on Information Technology Project and Internet Computing Project in 2002 in the School of Computer and Information Science at Edith Cowan University. In total thirty project teams were formed from 126 students. Each project team may have up to 5 members, and was allocated 14 weeks for completing its project. All project teams were required to develop a project proposal in the first 3 weeks. This proposal should include project requirements, systems analysis and design, feasibility and cost analysis, development and testing plan, hardware and software requirements for the project development, and if any, alternative options for the project development if the hardware and software requirements are not met. The remaining 11 weeks were allocated for project development, and final project presentation and demonstration. During the course, the project management for each project was done by the team leader and members with the close monitoring from the supervisor. Regular supervisor-team meetings were scheduled once a fortnight, with exceptions of immediate meeting called any time for discussing emergent events. Cases discussed below were encountered one or more incidents in human incompatibility during the course.

\section{Project A}

This project team was a reformed group with 5 students, in which there are 3 Australian students, and 2 Asian students with strong background in Chinese culture. An Australian student was elected to be the team leader. In the beginning of the semester, the supervisor noticed that this student has a very 'bossy' manner in working with other students, which had resulted in his exclusion from his initial team by other members. The supervisor reminded him of changing his 'bossy' leadership style in the new team even though no tension between the leader and members had occurred. When a student with western culture feels that the leader is dictating him/her, this student will react immediately and consequently a resolution can be reached. In contrast when a student with Chinese culture feels dictation from the leader, he/she often keeps quiet until the upmost tolerance. Once he/she speaks out, it means the final break-up of the collaboration. The supervisor made the leader aware of this fact so that any irreparable conflict could be avoided in the late stage. The team leader accepted the supervisor's advice and worked with his team members efficiently throughout the project, especially with the 2 Asian students. In the end of the pro- 
ject, the team leader made an emotional appreciation to the supervisor for guiding not only the project management, but also the interpersonal communications in a teamwork environment.

\section{Project B}

This project team consisted of 5 members with 3 female and 2 male students. The team elected a male student as the project leader who came from a Middle East country, and other members were with western traditions. One female member was working full time and could not come for most meetings called on weekdays whereas the team leader could not commit to any meetings on weekends due to religious and other reasons. When the submission deadline for project proposal was approaching, the team leader worked on the proposal overnight and then made phone calls to his team members at $4 \mathrm{AM}$ for a final meeting before the $8 \mathrm{AM}$ submission deadline. His action incurred anger from all the team members. The team leader explained to the supervisor that by his tradition whatever the difficulties the team may have, everyone should make the most effort to meet the deadline whenever it is needed. However, the others complained to the supervisor that by the western tradition overnight is private time, and any call during this time is breaching the privacy no matter what the reason of the call is. Moreover, they said they tried to arrange a meeting on the previous weekend to finalise the proposal but the team leader did not want to come for the meeting. Obviously this dispute was more 'social' than technical; thus the supervisor was not in a position to make a judgement on who should be responsible for this incident.

Since this occurred in the early stage of the project, the supervisor suggested them to allow the team leader to join another project and the 4 remaining members to form a new team to continue on the proposed project with a new team leader elected from them. However, these 4 students did not want the team leader to leave because he was the one who should take the major responsibility on Web programming. They promised to maintain a working relationship with the team leader for the rest of the project. The project was eventually completed, but the mutual respect had never been restored and small frictions often occurred during the course. In any measure, the management of this project was unsatisfactory.

\section{Project C}

This project team was formed with 5 members. After the first 2 weeks in discussion for developing the project proposal, two different opinions on implementation of the project were held by two factions in the team. Three students insisted on using Microsoft Access as the backend database linked with interfaces implemented using Visual Basic, whereas two other students wanted to implement the project using MySQL and PHP. Since this was purely a technical conflict in the team, the supervisor advised the students to break the team into two separate projects. Each team could use the same concept to develop its own proposal based on its selected implementation. The students accepted the supervisor's advice. Three students were permitted to work on the relatively 'easier' project using VB and Access whereas 2 other students with 2 more late-enrolled students worked on the MySQL-PHP based project. Both projects were successful in the end of the semester.

\section{Project D}

This project team had 4 students. The team proposed a project using a very complex software development model, instead of the simplified model recommended to all the students by the supervisor. The supervisor felt that the requirements set in this project proposal were higher than the normal standards for this study and assessed that there would be a need for every member in the team to be fully stretched to achieve the project goals. Therefore, the supervisor suggested the team to reconsider its project requirements, but the team was in full of confidence to achieve the goals. Indeed the progress in the first half of the project development was on target. However, in 
the second half, one member suddenly left the team, which led to the failure in fully achieving the project goals because each member had been fully loaded. In their project report, the 3 remaining members summarised what they learnt from this incident related to their ambitious project plan, which could be invaluable for their professional life in the future.

\section{Discussions and Conclusion}

The case of Project A exhibits that the leader's personality determines the adherence of a project team. It also shows that a team leader of a student project has no authority without the trust and respect from other team members. Awareness in cultural differences among students in a team is very helpful for a team leader to adopt an appropriate leadership style so as to ensure the efficient collaboration in a team with students with different cultures.

Project B demonstrates how important the mutual respect is for producing a quality project. The problems encountered in this case are partly due to the difference in cultural/religious backgrounds, and partly due to the incompatibility in individual member's personal commitments to the project. The supervisor still believes that allowing the team leader to joint another project should be the right advice to the students at that early stage. Unfortunately, the other 4 members insisted on keeping doing the proposed project together. Although the supervisor believed that the decision made by the students was not in the best interest of the student learning, their selfbelieved demand could not be denied. However, the supervisor did point out to the students the potential difficulties they might have in the coming stages of the project development and the consequences in working in a stressful environment.

In contrast to Project B, students in Project $\mathrm{C}$ that encountered different opinions from different members in project implementation accepted the timely advice given by the supervisor and broke the team into two separate projects, which led to the success of both projects.

The case of Project D demonstrates that a fully-stretched plan for achieving over-estimated project goals in a fixed period of time would always have a high level of risks during the course. It also shows that how severe the influence will be if a member suddenly leaves the project, in which every member is fully loaded or even overloaded. The positive side of this case is that students had a real example of failure in project development and management, from which they learnt more than from any successful stories.

In summary, the case studies demonstrate that this principle-tactics based practical guideline is useful and effective in guiding student handling human incompatibility in their project management and development. Under this guideline, giving students more responsibility in management can make students effectively learn more useful knowledge and skills from their own practice, which cannot be gained from reading books and thus will be invaluable for their professional activities in the future.

\section{References}

Boehm, B. (1988). A spiral model for software development and enhancement. IEEE Computers, 21 (5), 61-72.

Gustafson, D. (2002). Software engineering. McGraw-Hill.

Hall, E. (1998). Managing risk: Methods for software development. Addison-Wesley Longman.

Hartley, S. (2003). Project management: A competency-based approach. Pearson Prentice Hall.

Jones, C. (1994). Assessment and control of software risks. Prentice-Hall.

Ould, M. (1999). Managing software quality and business risk. John Wiley and Sons. 
Parnas, D. (1979). Designing software for ease of extension and contraction. IEEE Transactions on Software Engineering, 5 (3), 128-138.

Pressman, R. (2001). Software engineering: A practitioner's approach. McGraw-Hill.

Royce, W.W. (1970). Managing the development of large software systems: Concepts and techniques. Proceedings of IEEE WESTCON.

Sommerville, I. (2001). Software engineering. Addison-Wesley.

\section{Biography}

Dr. Wanwu Guo received his PhD degree from the University of Western Australia in 1999. He is currently a lecturer in computing and IT with the School of Computer and Information Science at Edith Cowan University in Australia. His research interests include artificial intelligence, distributed computing/information systems, software engineering, signal and image processing, programming, algorithm analysis, project management, computational geophysics, and earthquake seismology. 